\title{
Fractional Calculus in Electrical Impedance Spectroscopy: Poisson - Nernst - Planck model and Extensions
}

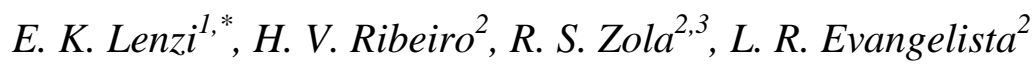 \\ ${ }^{1}$ Departamento de Fsica, Universidade Estadual de Ponta Grossa, Av. Carlos Cavalcanti, 84030-900 \\ Ponta Grossa - PR, Brazil \\ 2 Departamento de Física, Universidade Estadual de Maringá, Avenida Colombo, 87020-900 Maringá \\ - PR, Brazil \\ ${ }^{3}$ Departamento de Física, Universidade Tecnológica Federal do Paraná, 86812-460 Apucarana - PR , \\ Brazil \\ *E-mail: eklenzi@uepg.br
}

doi: $10.20964 / 2017.12 .61$

Received: 28 February 2017 / Accepted: 27 September 2017 / Published: 12 November 2017

\begin{abstract}
We review some analytical results obtained in the context of the fractional calculus for the electrical spectroscopy impedance, a technique usually employed to interpret experimental data regarding the electrical response of an electrolytic cell. We start by reviewing the main points of the standard Poisson - Nernst - Planck model. After, we present an extension that incorporates fractional time derivatives of distributed order to the diffusion equation. Then, we include fractional time derivatives on the boundary conditions in order to face the problems that are characterized, in the low frequency limit, by a frequency dispersion and, consequently, leads to a response in the form $Z: 1 /(i \omega)^{\gamma}$, where $Z$ is the electrical impedance, $\omega=2 \pi f$, with $f$ being the frequency of the applied voltage, and $0<\gamma \leq 1$. This scenario is extended in order to encompass also the systems characterized by Ohmic electrodes. For these cases, by focusing the low frequency regime, we discuss the applicability of such extensions as a tool to describe experimental data. This analsis is applied in the description of the electrical impedance of electrolytic cells with Milli - Q water and a weak eletrolytic solution of $\mathrm{KCl}$.
\end{abstract}

Keywords: fractional time derivative; boundary conditions; electrical response

\section{$\underline{\text { FULL TEXT }}$}

(C) 2017 The Authors. Published by ESG (www.electrochemsci.org). This article is an open access article distributed under the terms and conditions of the Creative Commons Attribution license (http://creativecommons.org/licenses/by/4.0/). 